\title{
VIABILIDADE DE SILAGEM DE MILHO PARA O GADO LEITEIRO
}

\author{
FEASIBILITY OF CORN SILAGE FOR DAIRY CATTLE
}

\author{
Eduardo Donizeti Scheler-Scheler_1000@hotmail.com \\ Faculdade de Tecnologia de Taquaritinga - Taquaritinga - São Paulo - Brasil \\ Fábio Alexandre Cavichioli - fabio.cavichioli@fatectq.edu.br \\ Faculdade de Tecnologia de Taquaritinga - Taquaritinga - São Paulo - Brasil \\ DOI: 10.31510/infa.v18i1.1095 \\ Data de submissão: $10504 / 2021$ \\ Data do aceite: 09/07/2021 \\ Data da publicação: 30/07/2021
}

\section{RESUMO}

De origem mexicana, o milho era plantado por Índios americanos em montes, usando um sistema complexo que variava a espécie plantada de acordo com o seu uso. A silagem de milho é hoje o tipo de silagem mais usado no Brasil. Isso acontece principalmente porque ela consegue fornecer forragem com muita energia e proteína para o gado, e tem seu cultivo mais fácil que outras culturas. A silagem de milho é um dos componentes mais importantes na alimentação de bovinos, uma vez que a sua planta fornece um grande volume de alimento palatável, com alta digestibilidade e rico em energia, o que resulta em um excelente potencial para produzir leite. O presente artigo tem como objetivo realizar a viabilidade de silagem de milho para o gado leiteiro por meio da análise econômica financeira através dos indicadores econômicos Valor presente líquido, Taxa interna de retorno e Payback.

Palavras-chave: Produção. Análise. Custo. Ruminantes.

\begin{abstract}
Of Mexican origin, the corn was planted by American Indians in heaps, using a complex system that varied the species planted according to its use. Corn silage is now the most used type of silage in Brazil. This is mainly because it manages to provide fodder with lots of energy and protein for cattle, and it is easier to grow than other crops. Corn silage is one of the most important components in the feeding of cattle, since its plant provides a large volume of palatable food, with high digestibility and rich in energy, which results in an excellent potential to produce milk. This article aims to realize the viability of corn silage for dairy cattle through the financial economic analysis through the economic indicators Net present value, Internal rate of return and Payback.
\end{abstract}

Keywords: Production. Analysis. Cost. Ruminants. 


\section{INTRODUÇÃO}

A silagem é um dos principais alimentos fornecidos aos bovinos de leite, especialmente, aos de alta produção. As forrageiras são armazenadas sem ar e conservadas em silos, reservatórios fechados, de construção acima ou abaixo do solo, próprios para armazenamento e conservação de grãos secos, sementes, cereais e forragens verdes. (ROGE, 2019).

O milho é uma forrageira tropical com alto potencial de produção de matéria seca por área e com alta capacidade de energia, o que proporciona a alta taxa de lotação animal acoplada ao baixo uso de alimentos concentrados por litro de leite produzido. A produção de leite à base de silagem de milho é uma forma de agregar valor a este grão na forma de produtos lácteos. Em algumas regiões a produção de silagem de milho é tradicional por não competir por máquinas, tempo da administração, mão de obra e local geográfico com a cultura do café. No entanto, a saída de produtores da atividade leiteira e o crescimento simultâneo da produção de milho grão em regiões historicamente produtoras de leite e café questiona a eficiência financeira do processo metabólico de transformar amido de milho em produtos lácteos de alto valor biológico. (PEREIRA, 2003).

A prática da ensilagem de grão úmido de milho foi introduzida no Brasil no início da década de 80, no Paraná (Kramer e Voorsluys, 1991). Essa tecnologia pode contribuir para solucionar problemas de armazenagem de grãos, quando normalmente ocorrem perdas qualitativas e quantitativas, em função do ataque de insetos, de microrganismos e de roedores. A colheita do milho para ensilar proporciona antecipação na retirada da cultura da lavoura com grandes benefícios num esquema de rotação de culturas, além de reduzir significativamente as perdas no campo (JOBIM, REIS, 2001).

Segundo o Instituto Brasileiro de Geografia e Estatística (IBGE, 2011), o Paraná é o terceiro maior produtor de leite do Brasil, com 3,5 bilhões de litros/ano. Em segundo vem o Rio Grande do Sul, com 3,6 bilhões, e em primeiro Minas Gerais, com 8,3 bilhões de litros/ano, sendo a região Sudoeste de Minas Gerais a maior produtora de leite. Neste cenário competitivo, em rebanhos de alta produção, a atividade leiteira depende muito do uso de milho como a principal fonte de energia. 


\section{WTEREFAEETEENOLOOGCA}

Hoje com o aumento do preço dos insumos os custos com a alimentação são bastante significativos na produção leiteira. O uso da silagem de grão úmido de milho tem se constituído em importante tecnologia para redução dos custos com alimentação em criações de bovinos leiteiros. Ultimamente vêm sendo demonstradas as vantagens zootécnicas e econômicas do uso de silagem de grão úmido de milho frente ao grão seco na alimentação de ruminantes. Aspectos relacionados à melhoria da digestibilidade ruminal e total do amido do milho ensilado sob a forma de grãos úmidos e ao menor custo comparado ao milho moído, têm favorecido sua utilização. (MEDINA, 2010).

O presente artigo tem como objetivo realizar a viabilidade de silagem de milho para o gado leiteiro por meio da análise econômica financeira através dos indicadores econômicos Valor presente líquido, Taxa interna de retorno e Payback.

\section{FUNDAMENTAÇÃO TEÓRICA}

\subsection{Cultura do milho}

O milho é uma cultura que responde em tecnologia e manejo. Aatualmente, existem híbridos que apresentam grande potencial produtivo, permitindo ao produtor boa rentabilidade. A escolha de híbridos é uma etapa crucial do planejamento, e esta deve ser baseada em informações das áreas, clima e problemas fitossanitários para escolha de materiais que contenham características desejáveis junto a essas informações. Os manejos a serem adotados dependem da expectativa de produção para cada lavoura e do monitoramento de pragas e doenças, o qual é fundamental dentro do conceito de manejo integrado, que possibilita direcionar esforços e realizar os manejos de maneira mais eficiente. Como a expectativa normalmente vem sendo alta, os produtores têm utilizado sementes de alto investimento, com biotecnologias embarcadas e tem havido grande preocupação na proteção do potencial produtivo com utilização de fertilizantes, herbicidas, inseticidas e fungicidas (AGRO, 2018).

Existem diferentes épocas de plantio do milho, de forma geral, nas regiões sul, sudeste e centro-oeste, a época mais indicada é de setembro a novembro, na região nordeste e partes da região norte, o plantio se concentra entre os meses de março a abril. Os plantios fora de época podem ser efetuados em muitas regiões, como é o caso do milho safrinha. Para poder 
fazer isso, o produtor necessita entender um pouco da fisiologia da planta do milho para saber como os fatores climáticos afetam e/ou influenciam o desenvolvimento do milho e em qual época essas limitações mais afetam as produções (CPT, 2017).

\subsection{Produção do milho para silagem}

Existem várias plantas forrageiras, anuais e perenes, que servem para a produção de silagem, o milho é uma das culturas mais utilizadas neste processo no Brasil por apresentar um bom rendimento de matéria verde, excelente qualidade de fermentação e manutenção do valor nutritivo da massa ensilada. Outras vantagens que o cereal proporciona são um baixo custo operacional de produção e uma boa aceitabilidade por parte dos animais. (CRUZ et al, 2019).

Segundo CRUZ et al (2019), a escolha de cultivares de porte alto com elevada produção de massa seca total como era utilizado no passado, mostrou-se inadequada principalmente devido à pequena porcentagem de grãos presentes na massa. Vários estudos mostram a importância da espiga na produção e na qualidade da planta do milho. Estes estudos mostram que o milho é responsável por aproximadamente $50 \%$ da produção total de matéria seca, a produção de grãos está geralmente correlacionada à produção de matéria seca total na planta. Há um consenso entre extensionistas e pesquisadores que define a planta ideal para ensilagem como sendo aquela que apresenta alto percentual de grãos na silagem, que contenha fibras de melhor digestibilidade e apresente alta produtividade de massa.

A silagem de milho é um alimento muito utilizado na pecuária leiteira devido à sua praticidade operacional, quando comparada, por exemplo, com a cana-de-açúcar, por conter excelentes características bromatológicas, entre outros aspectos positivos deste alimento. Poucos são os produtores que conhecem os reais valores para se produzir a silagem de milho, pois muitos acreditam ser um método de alto custo de produção. (SANTOS, 2016).

\subsection{Quantidade produzida por hectare}

A produção é realizada em uma área de 1 hectare, produzindo $50.000 \mathrm{~kg} / \mathrm{há}$ de silagem. Essa silagem será utilizada durante 120 dias. Tendo um consumo diário de aproximadamente 
417 quilos para um rebanho de 12 animais, consumindo $24 \mathrm{~kg}$ diários de silagem e $2 \mathrm{Kg}$ de ração concentrada por dia.

Haverá um rebanho de 12 bezerros que serão alimentados com $11 \mathrm{Kg}$ de Silagem por dia e $1 \mathrm{Kg}$ de ração concentrada/animal/dia.

\subsection{Custo de produção por hectare}

O custo de produção é dado por meio de dados e/ou registros dos gastos para se obter o produto final, (Tabela 1).

Tabela 1: Custos de produção de silagem de milho com diferentes produtividades.

\begin{tabular}{|c|c|c|}
\hline \multirow{2}{*}{ Custo/hectare } & \multicolumn{2}{|c|}{ Produtividade de massa verde/ha } \\
\hline & $35 \mathrm{t}$ & $50 \mathrm{t}$ \\
\hline Semente (1,3 sc/ha) & 455,00 & 585,00 \\
\hline Fertilizantes ${ }^{1}$ & 745,00 & 838,00 \\
\hline Defensivos & 310,00 & 310,00 \\
\hline Plantio² (máquinas e măo de obra) & 272,00 & 272,00 \\
\hline $\begin{array}{l}\text { Financeiros, remuneração da terra, } \\
\text { assistência técnica }\end{array}$ & 926,00 & 934,00 \\
\hline Custo total de implantaçåo & $2.708,00$ & 2.939 .00 \\
\hline $\begin{array}{l}\text { Ensilagem RS/ha - (máquinas, mão de obra e } \\
\text { transporte) })^{3}+\text { (custo de estocagem e silos) }\end{array}$ & $1.106,00$ & $1.268,00$ \\
\hline Custo total da silagem & 3.814 .00 & $4.207,00$ \\
\hline Produtividade de massa verde $\mathrm{kg} / \mathrm{ha}$ & 35.000 & 50.000 \\
\hline Produtividade de matéria seca $\mathrm{kg} / \mathrm{ha}$ ( $34 \% \mathrm{MS})$ & 11.900 & 17.000 \\
\hline Custo/tonelada de massa verde (RS) & 109,00 & 84,14 \\
\hline 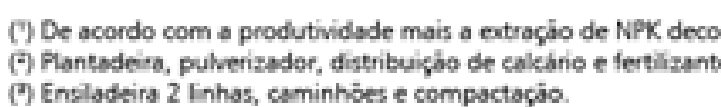 & remoşâo da palhad. & \\
\hline
\end{tabular}

Fonte: Pioneer Sementes, 2015 
$\mathrm{Na}$ tabela 1 observamos os custos de produção com diferentes produtividades em tonelada de massa verde por hectare, tendo o custo de $\mathrm{R} \$ 3.814,00$ para 35 toneladas e $\mathrm{R} \$$ $4.207,00$ para 50 toneladas.

\section{PROCEDIMENTOS METODOLÓGICOS}

Para a elaboração do presente artigo, foram realizadas pesquisas bibliográficas através das referências teóricas já analisadas e publicadas por meio de websites, jornais, revistas e artigos científicos.

\section{TIPOS DE SILO}

Os dados segundo a LONAX (2017), apresentam os tipos de silo:

Silo superfície: Esse é o tipo de silo mais barato e simples de ser construído. Ele oferece ao agricultor grande flexibilidade para abastecê-lo ou esvaziá-lo.

Silo trincheira: Sua forma trapezoidal e do baixo custo de construção, o silo trincheira é o modelo mais utilizado atualmente. Aproveitam-se os terrenos acidentados para construí-lo e revestir ou não as paredes e bases.

Silo bolsa: Esse modelo de armazenagem exige processos e equipamentos complexos para ser realizado. Dessa forma, há um grande custo inicial em sua utilização. Ele é confeccionado diretamente na fazenda, permitindo que o proprietário terceirize as máquinas para a sua produção.

Silo fardo: O silo fardo é encomendado e produzido de acordo com as exigências da produção. Assim, os produtores criam soluções para silagem adequadas às suas necessidades. Ele é uma unidade pequena, independente e que pode ser posicionada em qualquer lugar.

\subsection{Silo Trincheira para a fabricação da silagem}

Segundo Amaral \& Bernardes (2007), quando se decide construir um silo trincheira, os principais parâmetros que devem ser levados em consideração para respeitar o avanço diário da massa de silagem são:

- $\quad$ Dimensões mínimas do silo; 
- Quantidade retirada diariamente (avanço diário)

- Densidade da massa.

As dimensões mínimas estão associadas a exigência da mecanização durante a ensilagem, pois deve haver uma largura suficiente para descarregar os vagões que chegam da área rural e também permitir que o trator possa compactar a massa (silagem), assim, a largura não deve ser menor que 5 m. (AMARAL, BERNARDES, 2007).

Para respeitar a quantidade retirada diariamente a segunda variável importante se torna a altura do silo. Pois, deve-se ressaltar que o comprimento da estrutura (silo) não influencia na velocidade de avanço, mas depende da quantidade de silagem que deverá ser estocada para alimentar os animais. (AMARAL, BERNARDES, 2007).

\subsection{Colheita e manejo do milho}

Ainda que existam informações técnicas sobre o efeito do teor de matéria seca sobre a produção e a qualidade da silagem e também sobre o seu efeito na nutrição animal, os agricultores ainda têm dificuldades de realizar essa colheita no momento certo, exigindo principalmente dos órgãos de fomento e assistência técnica uma melhor estratégia de abordagem para a resolução desse problema. O milho para silagem é colhido antes de completar seu ciclo, ou seja, antes do milho atingir sua maturidade fisiológica, pois a hora da colheita afeta a produção de massa seca total e a composição relativa das diferentes partes da planta, principalmente a percentagem de grãos na massa seca total. O corte do milho antecipado para silagem, resulta em menor quantidade de grãos, aumenta os teores de fibras e reduz moderadamente os teores de energia da silagem (CRUZ et al, 2019).

Segundo CRUZ et al (2019), na maioria das situações, o produtor faz a opção pelo corte antecipado da planta mais verde por quatro motivos:

- $\quad$ Ensiladeira corta mais fácil

- Compactação no silo é facilitada

- $\quad$ Animais consomem mais

- $\quad$ Perdem-se menos grãos nas fezes. 


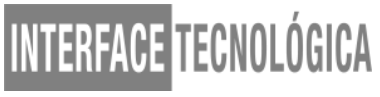

\section{RESULTADOS E DISCUSSÃO}

O custo para os procedimentos da silagem, incluindo desde as sementes e manejo do plantio até o manejo da silagem é de $\mathrm{R} \$ 7.230,14$. Para a realização dos trabalhos de abertura e cobertura do silo trincheira foram gatos $\mathrm{R} \$ 12.500,00$ e $\mathrm{R} \$ 28.700,00$ em Maquinários para manejo da plantação e da silagem, como mostra a tabela 2.

Tabela 2 - VPL de Silagem de milho para Gado Leiteiro.

\begin{tabular}{|c|c|c|c|c|c|}
\hline \multicolumn{6}{|c|}{ VPL Silagem de Milho para Gado Leiteiro } \\
\hline \multicolumn{2}{|l|}{ Investimento } & & & \multicolumn{2}{|l|}{ Receita } \\
\hline Custo Silo: & RS $12.500,00$ & & & Leite: & R\$ $193.959,36$ \\
\hline Custo Máquin as: & R\$ $28.700,00$ & & & & \\
\hline Total Investimento: & $\mathrm{R} \$ \mathbf{4}^{1.200,00}$ & & & & \\
\hline \multicolumn{6}{|l|}{ Custos Fixos } \\
\hline Custo de Manejo: & RS $7.230,14$ & & & & \\
\hline Salários $+80 \%$ encargos: & RS $5.400,00$ & & & & \\
\hline Total Custos Fixos: & $\mathrm{R} S \mathbf{1 5 1 . 5 6 1 , 6 8}$ & & & & \\
\hline \multicolumn{6}{|l|}{ Custos Variáveis } \\
\hline Custos Variáveis & $\mathrm{R} \$ 150,00$ & & & & \\
\hline \multicolumn{2}{|l|}{ Ração: } & & & & \\
\hline \multicolumn{2}{|l|}{ Vacinação: } & & & & \\
\hline \multicolumn{2}{|l|}{ Limpeza e Higiene: } & & & & \\
\hline \multicolumn{2}{|l|}{ Combustivel: } & & $\mathrm{FC}$ & RS $14.792,88$ & \\
\hline \multicolumn{2}{|l|}{ Total Custos Variáveis: } & & & & \\
\hline \begin{tabular}{|l} 
ANOS \\
\end{tabular} & 0 & 1 & 2 & 3 & 4 \\
\hline FC & $41.200,00$ & RS $14.792,88$ & RS $14.792,88$ & RS $14.792,88$ & RS $14.792,88$ \\
\hline FCAC & $41.200,00$ & -RS $26.407,12$ & -RS $11.614,24$ & RS $\quad 3.178,64$ & RS $17.971,52$ \\
\hline \multirow{2}{*}{$\begin{array}{l}\text { FCDesc } \\
\text { FCAcDesc } \\
\end{array}$} & $41.200,00$ & RS $13.326,92$ & RS $12.006,23$ & RS $10.816,43$ & RS $9.744,53$ \\
\hline & -RS $41.200,00$ & -RS $27.873,08$ & -RS $15.866,85$ & -RS $\quad 5.050,42$ & RS $4.694,11$ \\
\hline \multirow[t]{2}{*}{ i } & $11 \%$ & & & & \\
\hline & & & & & \\
\hline VPL & $4.694,11$ & & & & \\
\hline TIR & $16 \%$ & & & & \\
\hline Payback Simples & 2 anos & 9,421483849 & meses & 12.64451547 & dias \\
\hline Payback Desc. & 3 anos & 6,219393689 & meses & 6,581810683 & dias \\
\hline
\end{tabular}

Fonte: elaborado pelos autores (2020)

Os componentes de custo de produção para silagem de milho são: preparo do solo, plantio, trato cultural ou manejo, colheita e ensilagem. As etapas com maior influência no custo de produção são as etapas de plantio com $31 \%$ e trato cultural com $33 \%$, as demais etapas como, 


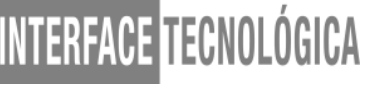

preparo de solo, colheita e ensilagem tem a participação na produção com cerca de $11 \%$ e $25 \%$, respectivamente (SENAR, 2019).

Segundo Rodrigo Knolseisen (2019), o milho é a melhor opção para ser feita a silagem, por ser uma planta que permite uma boa fermentação e consequentemente uma boa conservação do material ensilado, sendo que suas principais características para ensilagem são:

- $\quad$ Teor de matéria seca entre $30 \%$ a $35 \%$;

- $\quad$ No mínimo 3\% de carboidratos solúveis na matéria original;

- $\quad$ Baixo poder tampão;

- $\quad$ Boa fermentação microbiana.

Esses fatores garantem uma grande eficiência alimentar, trazendo uma maior produção diária de leite, se for comparado com silagens de sorgo ou cana de açúcar, a silagem de milho se torna um produto com grande valor nutricional, tendo um alto teor de energia e bom nível de digestibilidade.

Segundo a Revista Agropecuária (2019), a silagem de milho para alimentação animal surgiu como uma estratégia para suprir as necessidades nutricionais dos animais em períodos mais secos. A qualidade da silagem sofre variações com o passar dos anos. No início a prioridade era produzir a maior quantidade possível de massa verde por hectare. Sendo assim, o objetivo era reduzir os custos de produção do alimento. Com o passar dos anos houveram melhorias no padrão genético das vacas e com isso, houve o entendimento de que a produção de silagens com maior proporção de grãos seria a melhor alternativa para a alimentação dos animais. Isso, porque as silagens com maior proporção de grãos são mais digestíveis do que as que contém somente folhas e colmos.

Ainda segundo a Revista Agropecuária (2019), nesse período, o milho se tornou uma das matérias-primas mais utilizados para o processo de silagem. As principais justificativas são:

- $\quad$ Alto valor nutritivo;

- Conversão alimentar;

- Boa aceitação pelos animais;

- Custos razoáveis de produção. 


\section{CONCLUSÃO}

Após a análise dos custos utilizando os indicadores financeiros VPL, TIR e Payback o projeto viabilidade de silagem de milho para o gado leiteiro é considerado viável. Devido ao VPL (Valor Presente Líquido) ser positivo (R \$ 4.694,11) e a TIR (Taxa Interna de Retorno) ser maior que a TMA (Taxa Mínima de Atratividade) 16\%>11\%, concluiu-se que em uma projeção de 4 anos, o retorno do investimento será aproximadamente em 2 anos e 9 meses.

\section{REFERÊNCIAS}

AGRO BAYER BRASIL. 2018. Cultura do milho. Disponível em:

$<$ https://www.agro.bayer.com.br/culturas/milho>. Acesso em: 08 fev. 2021.

AMARAL, R. C; BERNARDES, T. F. 2007. Como dimensionar o silo trincheira.

Disponível em: $<$ https:/www.milkpoint.com.br/artigos/producao/como-dimensionar-o-silotrincheira-33659n.aspx>. Acesso em: 30 jan. 2021.

CPT. Plantio de milho - saiba qual é a época adequada para se plantar milho em todas as regiões do país. Disponível em: $<$ https://www.cpt.com.br/noticias/plantio-de-milho-saibaqual-e-a-epoca-adequada-para-se-plantar-milho-em-todas-as-regioes-do-pais $>$. Acesso em: 12 fev. 2021

CRUZ, J. C; FILHO, I. A. P; NETO, M. M. G. Milho para Silagem. Disponível em:

$<$ http://www.agencia.cnptia.embrapa.br/gestor/milho/arvore/CONT000fy $779 \mathrm{fnk} 02 \mathrm{wx} 5 \mathrm{ok} 0 \mathrm{pv}$ o4k3j537ooi.html>. Acesso em: 02 fev. 2021

EDUCA POINT. Silagem de milho: compensa usar snaplage? Disponível em: $<$ https://www.educapoint.com.br/noticias/fracoes-milho-valor-nutricional/>. Acesso em: 01 fev. 2021.

FUNDAÇÃO ROGE. Tipos diferentes de silo: vantagens e desvantagens. Disponível em: $<$ https://www.fundacaoroge.org.br/blog/tipos-diferentes-de-silo-vantagens-e-desvantagens $>$. Acesso em: 18 fev. 2021.

GODOI, C. R; SILVA, E. F. P. Silagem de milho como opção de volumoso aos ruminantes. PUBVET, Londrina, V. 4, N. 14, Ed. 119, Art. 808, 2010. Disponível em: $<$ file://C:/Users/Usuario/Downloads/silagem-de-milho-como-opccedilatilde.pdf $>$. Acesso em: 08 fev. 2021.

KNOLSEISEN, R. 2019. Silagem de milho - O volumoso suplementar mais usado para gado leiteiro no Brasil. Disponível em: $<$ https://gerencialeite.com.br/blog/silagem-de-milho/ >. Acesso em: 14 fev. 2021. 
LONAX-ADIMIN. 2017. Conheça os diferentes tipos de silo e suas vantagens. Disponível em: <https://www.lonax.com.br/conheca-os-diferentes-tipos-de-silo-e-suas-vantagens/>. Acesso em: 06 fev. 2021.

MEDINA, I. M; NATEL, A. 2010. Silagem de grão úmido - milho - Parte 2 de 2. Disponível em: $<$ https://www.milkpoint.com.br/artigos/producao/silagem-de-grao-umidomilho-parte-2-de-2-68116n.aspx>. Acesso em: 06 fev. 2021.

PEREIRA, J. Silagem de Milho com Menor Custo se faz com Produtividade. Disponível em: <http://www.pioneersementes.com.br/blog/43/silagem-de-milho-com-menor-custo-sefaz-com-produtividade $>$. Acesso em: 08 fev. 2021.

PEREIRA, M. 2003. Uma comparação financeira simples entre milho grão e milho silagem. Disponível em: <https://www.milkpoint.com.br/artigos/producao/uma-comparacaofinanceira-simples-entre-milho-grao-e-milho-silagem-15938n.aspx $>$. Acesso em: 20 jan. 2021.

REVISTA AGROPECUÁRIA. 2019. Silagem de milho: Uma alternativa para nutrir o rebanho!. Disponível em: <http://www.revistaagropecuaria.com.br/2019/11/11/silagem-demilho-uma-alternativa-para-nutrir-orebanho/?pagina $=$ posts $\&$ ano $=2019 \&$ mes $=05 \&$ dia $=08 \& u r l=$ silagem-de-milho-naalimentacao-animal-muita-energia-e-proteina-para-o-gado>. Acesso em: 14 fev. 2021.

SANTOS, G. 2016. Qual é o custo para produzir silagem de milho?. Disponível em: $<$ http://www.ccprleite.com.br/br/p/132/qual-e-o-custo-para-produzir-silagem-de-milho.aspx>. Acesso em: 02 fev. 2021.

SENAR. Silagem de milho, otimizando processos a fim de aumentar eficiência na atividade. Disponível em: <http://www2.senar.com.br/Noticias/Detalhe/11170>. Acesso em: 18 jan. 2021. 